\title{
Neutrophil Recruitment by Fetal Porcine Endothelial Cells: Implications in Scarless Fetal Wound Healing
}

\author{
OLUYINKA O. OLUTOYE, XI ZHU, DARRELL L. CASS, AND C. WAYNE SMITH \\ Michael E. DeBakey Department of Surgery [O.O.O., X.Z. D.L.C.] and the Department of Pediatrics \\ [O.O.O., D.L.C., C.W.S.], Baylor College of Medicine, Houston, TX 77030
}

\begin{abstract}
Fetal dermal wounds heal scarlessly and with a minimal inflammatory response. When a robust inflammatory response is induced at the site of fetal dermal wounds by the application of cytokines, healing results in fibrosis. To test the hypothesis that the reduced inflammatory response in fetal wounds is due to impaired fetal leukocyte-endothelial interactions, the contributions of fetal endothelial cells to the inflammatory response in the fetus were investigated. Endothelial cells isolated from blood vessels of adult and mid-gestational fetal pigs were cultured in media until confluent monolayers were established. Adult porcine neutrophils were isolated and resuspended at a concentration of 1 million cells $/ \mathrm{mL}$. Interactions between neutrophils and endothelial cells were observed under static and flow conditions. Endothelial monolayers were exposed to neutrophils with and without prior stimulation of the endothelial cells with tumor necrosis factor $\alpha$ (TNF- $\alpha$ ) for $4 \mathrm{~h}$. The neutrophil-endothelial interactions were observed and analyzed for neutrophil adhesion,
\end{abstract}

\section{ABSTRACT}

rolling velocity, and transmigration. Endothelial P-selectin mRNA expression was determined by real-time polymerase chain reaction (PCR). A novel in vitro model of fetal inflammation is described. Both adult and fetal endothelial cells demonstrated a dose-dependent increase in neutrophil adhesion and transmigration with increasing doses of TNF- $\alpha$. The fetal response was significantly lower than the adult. As expected, rolling velocity was lower at higher cytokine concentrations and had an inverse correlation with P-selectin mRNA expression. Fetal endothelial cells are less permissive to adhesion and transmigration of neutrophils than adult endothelial cells. This may contribute to the paucity of inflammation seen in the fetal response to dermal injury. (Pediatr Res 58: 1290-1294, 2005)

\section{Abbreviations}

GAPDH, glutaraldehyde phosphate dehydrogenase TNF- $\alpha$, tumor necrosis factor
Following injury, the body repairs the injured tissue by the mobilization of cells, release of factors, and deposition of matrix. The result is the manufacture of new tissue (scar) with architecture and functional properties that are inferior compared with the uninjured tissue (1). This wound-healing process is well defined in adult mammals. Wound healing occurs via a process of concurrent cellular and biochemical events: hemostasis, inflammation, proliferation, and remodeling. Adult dermal wound healing is characterized by a robust inflammatory response, recruitment and proliferation of fibroblasts and keratinocytes, deposition of collagen and other matrix proteins with the resulting fibrosis, and formation of a scar that is

Received January 12, 2005; accepted May 3, 2005

Correspondence: Oluyinka O. Olutoye, M.B.Ch.B., Ph.D., Division of Pediatric Surgery, Michael E. DeBakey Department of Surgery, Baylor College of Medicine, 6621 Fannin, CC 650.00, Houston TX 77030-2399: e-mail: oolutoye@bcm.tmc.edu

Supported in part by Robert Wood Johnson Foundation Amos Medical Faculty Development Fund \#43485 (O.O.O.), National Institutes of Health GM 069912 (O.O.O.), HL 070357 (C.W.S.), and HL 42550 (C.W.S.), The Curtis Hankamer Basic Research Fund (O.O.O.)

DOI: 10.1203/01.pdr.0000184326.01884.bc histologically and functionally distinct from the uninjured skin $(1,2)$. In contrast, fetal dermal wound healing is an efficient and rapid process in which essential amounts of matrix are deposited in the absence of a robust inflammatory response. There is a restoration of tissue architecture such that the fetal wound is barely distinguishable from the uninjured tissue and thus the fetus is said to heal scarlessly (3-7). While lower animals (reptiles and amphibians) are known to possess regenerative properties, only the mammalian fetus in early gestation appears to simulate this (3). The process of fetal wound healing has therefore been an area of investigation for several years.

One of the major distinguishing factors in the early phase of fetal dermal wound healing is the paucity of an acute inflammatory response. When a robust inflammatory response is evoked by the application of bacteria or cytokines, fibrosis ensues (8-10). It therefore appears that in the fetal dermis, the presence or absence of acute inflammation correlates with the presence or absence of fibrosis. We therefore embarked on this study to determine the factors in the fetus that may modulate the fetal inflammatory response. The endothelium is crucial to the process of leukocyte capture and transmigration (11) in 
inflammatory states. To test the hypothesis that the reduced inflammatory response in fetal wounds is due to impaired leukocyte-endothelial interactions, the contributions of fetal endothelial cells to the inflammatory response in the fetus was investigated using a novel model of fetal inflammation.

\section{MATERIALS AND METHODS}

Animals. Time-dated, pregnant, cross-bred swine (Department of Corrections, Huntsville, TX) were purchased and housed at the animal care facility. All animals were handled in accordance with the guidelines of the Baylor College of Medicine Institutional Animal Care and Use Committee. At d 60 of gestation (term $=115 \mathrm{~d}$ ), the pregnant sows were anesthetized (pentobarbital, ketamine, and isoflurane) and underwent a laparotomy. Fetal access was achieved by surgical hysterotomy. Each fetus was euthanized by cervical transection and the sow euthanized by a barbiturate overdose. The animals were immediately dissected and the umbilical veins, inferior vena cava, and jugular veins harvested fresh. Whole blood was obtained from adult pigs for isolation of neutrophils.

Endothelial cell isolation and culture. Previously described methods for isolation of human umbilical (12) and adult canine (13) endothelial cells were modified (14). After the surrounding connective tissue had been carefully dissected away, fresh inferior vena cava, jugular, or umbilical veins were collected into tubes containing phosphate-buffered saline (PBS) with dextrose (D-PBS) containing 5\% penicillin-streptomycin (GIBCO) and 5\% Fungizone (GIBCO) and chilled on ice for transport from the operating room to the tissue culture facility. The veins were everted, exposing the endothelial surface, washed with warm D-PBS to remove any traces of blood, and incubated with $320 \mathrm{U} / \mathrm{mL}$ of collagenase in PBS (Roche Biochemicals, Indianapolis, IN) for $20 \mathrm{~min}$ at $37^{\circ} \mathrm{C}$ in a water bath. The endothelium was then gently abraded to ensure detachment of the endothelium from the vessel wall. The vessels are removed, and the endothelial cells suspended in culture medium [Dulbecco Modified Eagle Medium (DMEM, Sigma Chemical Co.)] containing 10\% fetal calf serum (Hyclone, Logan, UT), 5\% penicillin-streptomycin and 5\% Fungizone, plated onto fibronectin- $\left(5 \mu \mathrm{g} / \mathrm{cm}^{2}\right)$ and gelatin $(0.2 \%)$-coated tissue culture plates, and incubated at $37^{\circ} \mathrm{C}$ in a humidified atmosphere with $5 \% \mathrm{CO}_{2}$ until confluent. The confluent monolayer was confirmed to be endothelial cells by immunohistochemistry using a polyclonal rabbit anti-human antibody to von Willebrand factor (vWF) (data not shown). Only first- or second-passage cells were used for the experiments.

Neutrophil isolation. Whole blood was obtained from peripheral ear veins of healthy adult pigs and anticoagulated with citrate phosphate dextrose (CPD $0.14 \mathrm{~mL} / \mathrm{mL}$ of blood: Abbott, North Chicago, IL). The blood was then sedimented in $6 \%$ dextran (wt/vol in $0.87 \% \mathrm{NaCl}$; Spectrum Chemical, Gardena, CA) for $45 \mathrm{~min}$ at room temperature. Leukocyte-rich plasma was layered on Ficoll-Hypaque gradients and centrifuged at $300 \times g$ for $20 \mathrm{~min}$ at room temperature, as previously described $(15,16)$. The resulting granulocyteerythrocyte pellets were washed and resuspended in PBS pH 7.4 containing $0.2 \%$ dextrose (D-PBS) at a concentration of $1 \times 10^{6}$ cells $/ \mathrm{mL}$. The cell preparations, containing more than $90 \%$ neutrophil with greater than $90 \%$ viable by trypan blue exclusion, were maintained at $4^{\circ} \mathrm{C}$ until used, usually within $2 \mathrm{~h}$.

Adhesion assay under static conditions. Porcine adult and fetal endothelial cells grown to confluence on fibronectin-coated $\left(5 \mu \mathrm{g} / \mathrm{cm}^{2}\right) 25-\mathrm{mm}$ coverslips were treated with recombinant human TNF- $\alpha$ (R\&D Systems Inc., Minneapolis, MN) at either 200 or $1000 \mathrm{U} / \mathrm{mL}$ for $4 \mathrm{~h}$, washed in PBS, and immediately inserted into adherence chambers specifically made for use with an inverted microscope with phase-contrast optics. The chambers consisted of two metal plates designed to hold two 25 -mm round glass coverslips separated by a Sykes-Moore chamber O ring (Bellco Glass, Inc., Vineland, NJ). Within this closed compartment neutrophils could be observed as they contacted the porcine monolayer (11).

A freshly prepared neutrophil suspension was injected into the chamber until full and the interaction with the monolayer observed and videotaped. The neutrophils were permitted to settle on the monolayer for $500 \mathrm{~s}$. The number of neutrophils in contact with the monolayer was determined by counting at least five microscopic fields $(40 \times$ objective). The chamber was then inverted for an additional $500 \mathrm{~s}$ so only adherent cells remained attached to the monolayer. The percentage of cells remaining in contact with the monolayer was determined and expressed as the percentage of adherence.

The percentage of cells migrating through the endothelial monolayer was also determined using phase-contrast optics; neutrophils adherent to endothelium are round and appear refractile with a surrounding halo since they do not spread on the surface of endothelial cells. In contrast, the neutrophils become flattened after migrating to a position between the monolayer and the substratum where they lose their refractile appearance (11).

Adherence assay under continuous flow. Neutrophil adherence to cytokine-stimulated adult and fetal porcine endothelial cells was assessed under continuous flow conditions, as previously described (17-19). First-passage endothelial cells were grown to confluence on fibronectin-coated 35-mm tissue culture dishes and treated with recombinant human TNF- $\alpha$ for $4-6 \mathrm{~h}$ before the experiments. Monolayers were washed in DPBS with $\mathrm{Ca}^{2+}$ and $\mathrm{Mg}^{2+}$, mounted in parallel flow chambers, and perfused with D-PBS for 2-3 min to remove all soluble factors. Unstimulated neutrophils were added to the feed line at a final concentration of $1 \times 10^{6} / \mathrm{mL}$ and perfusion continued for $10 \mathrm{~min}$ maintaining a shear stress of approximately 2 dynes $/ \mathrm{cm}^{2}(0.325 \mathrm{~mL} / \mathrm{min})$. A temperature-controlled Lucite box ensured that all flow experiments were performed at $37^{\circ} \mathrm{C}$. Interactions between the neutrophils and the endothelial monolayer were observed by phase-contrast videomicroscopy (Diaphot-TMD microscope, Nikon Inc., Garden City, NY) and CCD video camera (Sony Corp., Park Ridge, NJ) and quantified with a digital imaging processing system (Optimas; BioScan, Edmonds, WA). For each experiment, approximately six fields of view were recorded with a $20 \times$ objective for $2 \mathrm{~min}$ at $20 \mathrm{~s}$ per field. The total number of neutrophils interacting with the monolayer were determined and referenced per square millimeter of endothelial monolayer. For the purpose of the current study, interacting cells were defined as cells rolling at a velocity less than the flow stream plus those that are arrested. Rolling cells move more than one cell diameter during a 1.0-s interval as determined by time-lapsed digital subtraction techniques. The number of arrested cells was derived from the arithmetic difference between the number of interacting and rolling cells.

Real-time quantitative polymerase chain reaction (PCR). P-selectin mRNA expression was determined by real-time quantitative PCR. Control and TNF- $\alpha(1000 \mathrm{U} / \mathrm{nm})$ treated, adult and fetal porcine endothelial cells were harvested from tissue culture. Cells were lysed in $1 \mathrm{~mL}$ of TRIzol Reagent (Invitrogen, Carlsbad, CA) and $200 \mu \mathrm{L}$ chloroform. Total RNA was extracted and precipitated according to the manufacturer's protocol. The isolated RNA was immediately stored at $-80^{\circ} \mathrm{C}$ until used.

PCR reactions were performed in the iCycler iQ Real-Time PCR Detection System (Bio-Rad Laboratories, Inc., Hercules, CA). PCR amplifications were performed in a total volume of $20 \mu \mathrm{L}$, containing $1 \mu \mathrm{L}$ of cDNA sample, 4 $\mathrm{mM} \mathrm{MgCl} 2,0.2 \mu \mathrm{M}$ primers, $0.4 \mathrm{mM}$ each dNTPs (dATP, dCTP, dGTP, and dTTP), $0.025 \mathrm{U} / \mu \mathrm{L}$ Taq DNA polymerase, JumpStart Taq antibody and SYBR Green I. The primer pairs were as follows: P-selectin (forward) CACCAGCTCCAGTCTGTCAAG and (reverse) CTCCAGTTCCCCGTCTCCAA (184 bp) and glutaraldehyde phosphate dehydrogenase (GAPDH) (forward) CTACTGCCAACGTGTCGGTT and (reverse) CCTGTTGCTGTAGCCAAATTCATT (263 bp). Each PCR amplification was performed in triplicate wells, using the following conditions: $8 \mathrm{~min}$ and $30 \mathrm{~s}$ at $95^{\circ} \mathrm{C}, 15 \mathrm{~s}$ at $95^{\circ} \mathrm{C}$, and $60 \mathrm{~s}$ at $60^{\circ} \mathrm{C}$ repeated for a total of 40 cycles.

To generate the copy number for cDNA standards, porcine P-selectin and GAPDH cDNA were cloned from adult porcine platelets. Plasmids containing cDNA inserts were purified from bacterial cultures according to the manufacturer's protocol (Qiagen, Germany). Following the confirmation of the sequence by automated sequencing, the plasmids were digested with the appropriate restriction enzymes to generate the copy-number template standards for porcine P-selectin and GAPDH mRNAs. The expected fragments were eluted according to the manufacturer's protocol (Qiagen). The concentrations of the cDNA fragments were determined spectrophotometrically. Copy numbers of cDNA were empirically determined using the following equation: Copy number of $\mathrm{cDNA}$ standard $=$ mole $\times$ Avogadro Constant $=$ grams $/$ fragment molecular weight $\times$ Avogadro Constant $($ Avogadro Constant $=6.0221367 \times$ $\left.10^{23}\right)$.

The quantified cDNA fragments were later serially diluted in log increments and were used as known copy-number template standards in quantitative PCR. Reverse-transcriptase negative controls (samples containing RNA to which reverse transcriptase was not added) were included to exclude PCR amplification of contaminating genomic DNA. The housekeeping gene GAPDH was used as internal control to normalize for inefficiencies in cDNA synthesis and RNA input amounts. The results are reported as the ratio of P-selectin to GAPDH copy numbers.

Statistics. Results are reported as mean \pm SEM. An unpaired two-tailed $t$ test was used for statistical analysis. Significance was set at $p<0.05$.

\section{RESULTS}

Using a modification of the human umbilical vein endothelial cell (HUVEC) isolation techniques, we were able to isolate and establish primary cultures of fetal porcine umbilical vein 
endothelial cells (PUVEC) and adult porcine vena cava and jugular vein endothelial cells (PVEC). The interaction of fetal endothelial monolayers (PUVEC) and adult endothelial cells (PVEC) with neutrophils was compared under static conditions and with continuous flow.

When unstimulated, both adult and fetal endothelial cells had minimal interaction with adult neutrophils under static conditions $\left(5.2 \pm 1.9\right.$ and $5.7 \pm 2.0 \mathrm{cell} / \mathrm{mm}^{2}$, respectively) and no interaction at all with continuous flow. Compared with controls, a dose-dependent increase in the number of adherent neutrophils is noted when both adult and fetal endothelial cells are stimulated with TNF- $\alpha$ at 200 and $1000 \mathrm{U} / \mathrm{mL}$ under static conditions. While the percentage of interacting neutrophils that remained adherent significantly increased with the higher concentration of TNF- $\alpha$ applied to adult endothelial cells, no statistically significant difference in adherence was noted in fetal endothelial cells stimulated with either 200 or $1000 \mathrm{U} / \mathrm{mL}$ of TNF- $\alpha$ (Fig. 1). However, at both concentrations tested, fetal endothelial cells recruited significantly fewer neutrophils compared with adult endothelial cells under static conditions (Fig. 1) or with continuous shear stress (Fig. 2). A dosedependent and statistically significant increase in neutrophil adhesion to both adult and fetal endothelial cells was noted under conditions of continuous shear stress with increasing concentration of TNF- $\alpha$ (Fig. 2).

Under static conditions, the proportion of adherent neutrophils that actually transmigrated through the endothelial monolayer was significantly higher in the adult endothelial monolayer compared with the fetus, only at the higher concentration of TNF- $\alpha$. While a dose-dependent increase in the ratio of transmigrated neutrophils was observed with adult endothelial cells, with the fetal cells, there was no significant difference in the proportion of neutrophils that transmigrated in response to the different concentrations of TNF- $\alpha$ (Fig. 3). In contrast, under continuous shear stress conditions, no significant dose-

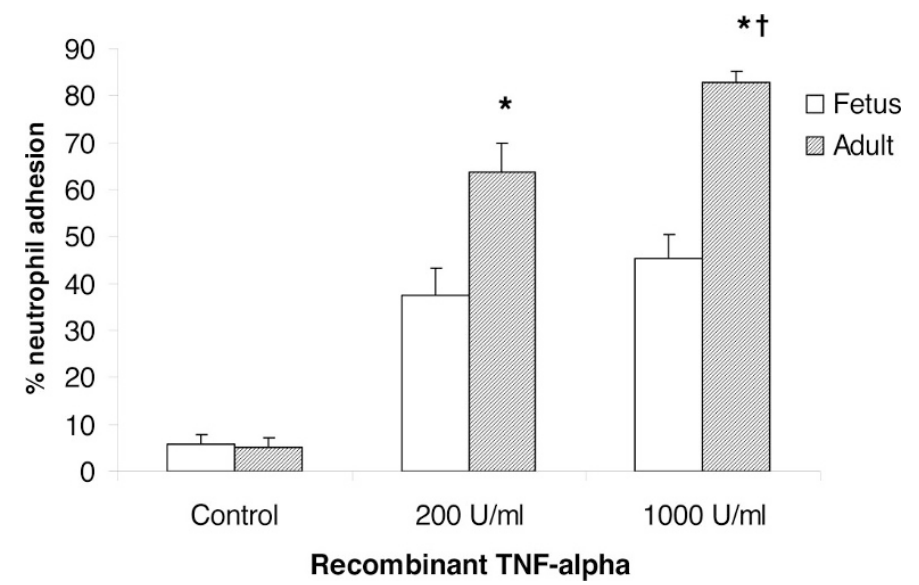

Figure 1. Interaction of fetal and adult endothelial monolayers with neutrophils under static conditions. Without stimulation (control), both fetal and adult endothelial cells had minimal interaction with adult neutrophils $(5.7 \pm 2.0 \%$ and $5.2 \pm 1.9 \%$, respectively). Neutrophil adhesion to fetal and adult endothelial cells stimulated with TNF- $\alpha$ at $200 \mathrm{U} / \mathrm{mL}$ concentration was $37.4 \pm$ $5.7 \%$ and $63.6 \pm 6.3 \%$, respectively. Neutrophil adhesion to fetal and adult endothelial cells at $1000 \mathrm{U} / \mathrm{mL}$ was $45.5 \pm 5.1 \%$ and $83.0 \pm 2.1 \%$, respectively. $* p<0.05$ compared with fetuses at both doses. $\dagger p<0.05$ compared with $200 \mathrm{U} / \mathrm{mL}$. Data represent mean \pm SEM of seven to 10 experiments.

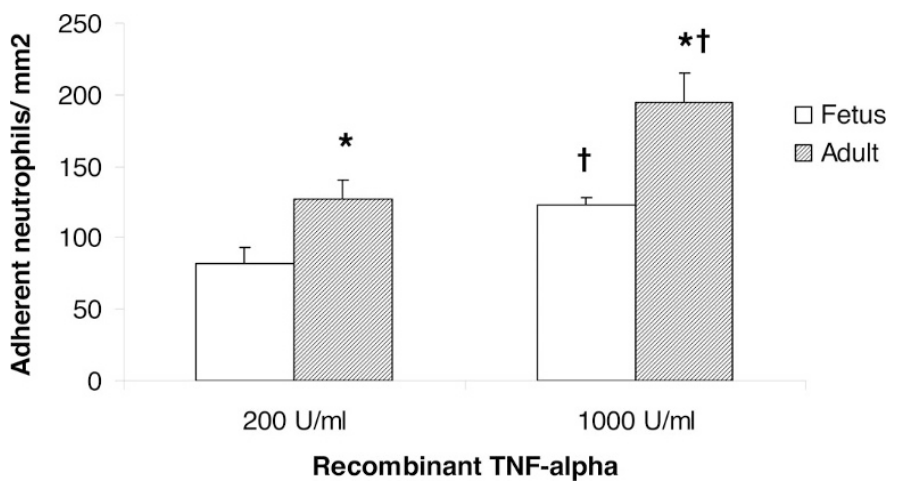

Figure 2. Interaction of fetal and adult endothelial monolayers with neutrophils under continuous flow conditions. When unstimulated (control), both fetal and adult endothelial cells had no interaction with neutrophils. In contrast, when monolayers were stimulated with TNF- $\alpha$ at $200 \mathrm{U} / \mathrm{mL}$ concentrations, $82.4 \pm 10.6$ and $127.0 \pm 13.7$ neutrophils $/ \mathrm{mm}^{2}$ were adherent to fetal and adult monolayers, respectively. At $1000 \mathrm{U} / \mathrm{mL}$ of TNF- $\alpha, 122.5 \pm 6.0$ and $195.1 \pm 19.7$ neutrophils $/ \mathrm{mm}^{2}$ were adherent to fetal and adult monolayers, respectively. ${ }^{*} p<0.05$ compared with fetuses at both doses. $\dagger p<0.05$ compared with $200 \mathrm{U} / \mathrm{mL}$. Data represent mean \pm SEM of 12 experiments.

dependent increase in the number of transmigrating cells could be observed. However, at the higher concentration of TNF- $\alpha$, adult endothelial cells induced transmigration of significantly more neutrophils than fetal endothelial cells (Fig. 4). Under both static and flow conditions, no transmigration of neutrophil is observed in the absence of endothelial cell cytokine stimulation.

Under flow conditions, leukocytes interacting with the endothelial surface move at a velocity slower than the flow stream. This is a crucial step in the diapedesis and ultimate attachment and transmigration of leukocytes from the bloodstream in vivo. The greater the degree of neutrophil interaction is with the monolayer, the slower the rolling velocity before ultimate firm adhesion to the endothelial monolayer. Thus, endothelium that would support diapedesis in vivo would

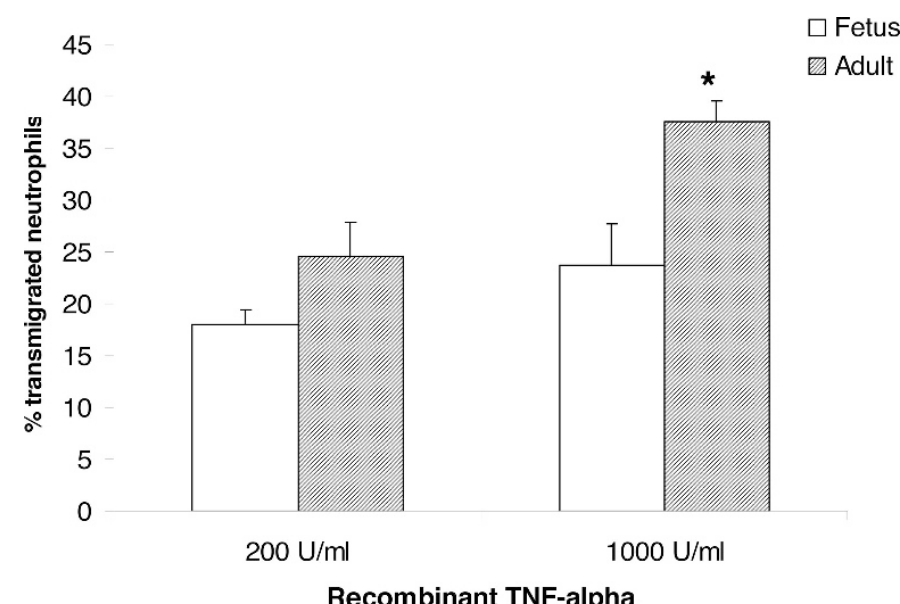

Figure 3. Transmigration of neutrophils through fetal and adult endothelial monolayers under static conditions. There was no transmigration through both unstimulated fetal and adult endothelial monolayers. After endothelial stimulation with TNF- $\alpha$, the percentage of neutrophils migrating through the fetal and adult endothelial monolayers were $18.0 \pm 1.4 \%$ and $24.5 \pm 3.4 \%$, respectively, at $200 \mathrm{U} / \mathrm{mL}$, and $23.7 \pm 4.0 \%$ and $37.5 \pm 2.0 \%$, respectively, at $1000 \mathrm{U} / \mathrm{mL}$. $* p<0.05$ compared with fetus at $1000 \mathrm{U} / \mathrm{mL}$ of TNF- $\alpha$. Data represent mean \pm SEM of six experiments. 


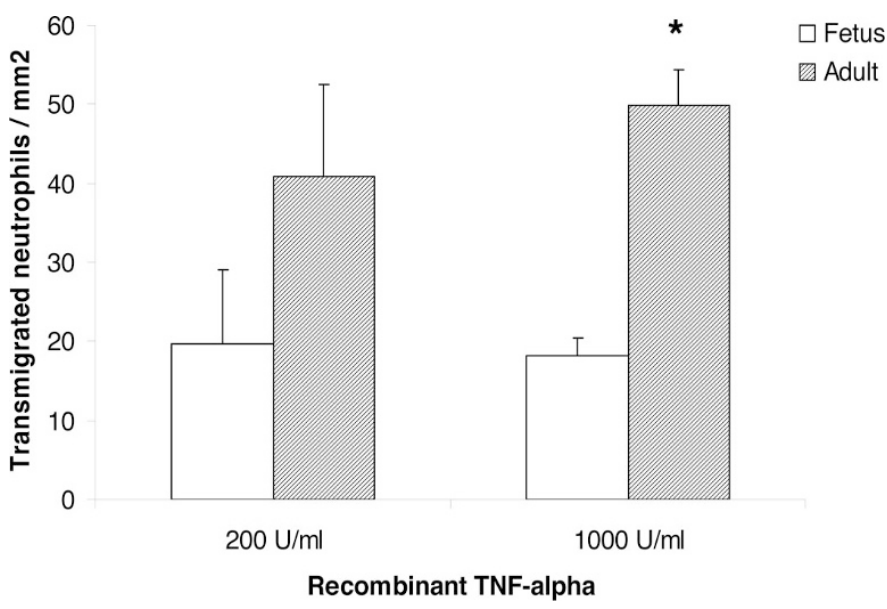

Figure 4. Transmigration of neutrophils through fetal and adult endothelial monolayers under continuous flow conditions. There was no transmigration through both unstimulated fetal and adult endothelial monolayers under flow. After endothelial stimulation with TNF- $\alpha$, neutrophils migrating through the fetal and adult endothelial monolayers were $19.7 \pm 9.5$ and $40.8 \pm 11.7$ neutrophils $/ \mathrm{mm}^{2}$, respectively, at $200 \mathrm{U} / \mathrm{mL}$ and $18.1 \pm 2.3$ and $49.9 \pm 4.5$ neutrophils $/ \mathrm{mm}^{2}$, respectively, at $1000 \mathrm{U} / \mathrm{mL}$. $* p<0.05$ compared with fetus at $1000 \mathrm{U} / \mathrm{mL}$ of TNF- $\alpha$. Data represent mean \pm SEM of six experiments.

manifest a slower rolling velocity of the leukocytes flowing across its surface. Figure 5 shows the rolling velocity of neutrophils across adult and fetal endothelial monolayers stimulated with increasing concentrations of TNF- $\alpha$. No rolling is observed in the control (unstimulated) group. There is an inverse correlation of the rolling velocity with increasing doses of TNF- $\alpha$ stimulation. Increasing the TNF- $\alpha$ concentration from 200 to $1000 \mathrm{U} / \mathrm{mL}$ significantly decreased rolling velocity on adult endothelial cells. There was no significant difference in the rolling velocity across fetal endothelial cells at both concentrations. However, at both the 200 and $1000 \mathrm{U} / \mathrm{mL}$ concentrations, neutrophil rolling velocity was significantly lower on adult endothelial cells compared with fetal endothelial cells.

Rolling, the initial phase of leukocyte endothelial interaction, is mediated primarily by the selectins, particularly Pselectin. The expression of P-selectin mRNA in unstimulated

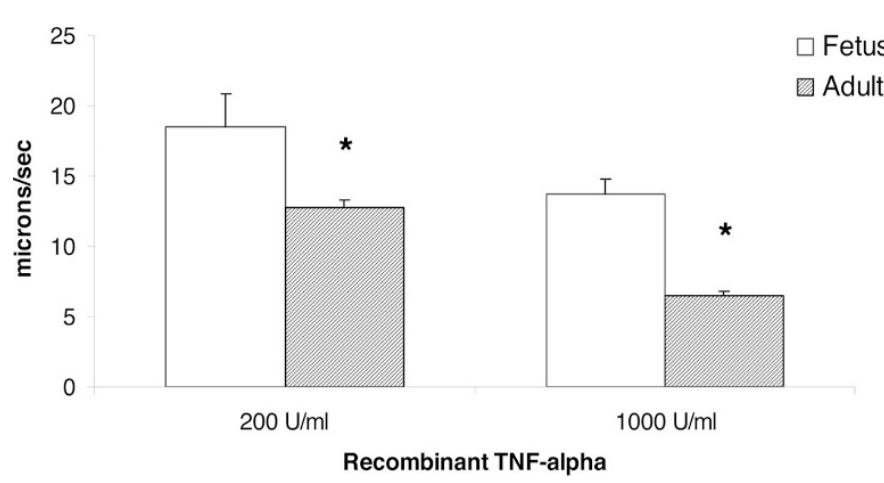

Figure 5. Rolling velocity of neutrophils on the surface of fetal and adult endothelial monolayers. After treating monolayers with 200 and $1000 \mathrm{U} / \mathrm{mL}$ of TNF- $\alpha$, the average velocity of neutrophils on the surface of fetal and adult endothelial monolayers was $18.6 \pm 2.3$ and $12.8 \pm 0.5 \mu \mathrm{m} / \mathrm{s}$, respectively, at $200 \mathrm{U} / \mathrm{mL}$ of TNF- $\alpha$ and $13.7 \pm 1.0$ and $6.5 \pm 0.4 \mu \mathrm{m} / \mathrm{s}$, respectively at 1000 $\mathrm{U} / \mathrm{mL}$. $* p<0.05$ compared with fetus at both doses. Data represent mean \pm SEM of seven to 10 experiments. adult and fetal endothelial cells was similar. Compared with control, both adult and fetal endothelial cells stimulated with TNF- $\alpha 1000 \mathrm{U} / \mathrm{mL}$ for $4 \mathrm{~h}$ mounted a significant increase in P-selectin mRNA expression. At this dose, P-selectin expression on adult porcine endothelial cells was three times that of fetal cells (Fig. 6).

\section{DISCUSSION}

The ability of leukocytes to migrate to the site of injury or inflammation is mediated by a complex series of events. The endothelial cell appears to play an integral role in this process. Release of pro-inflammatory mediators such as TNF- $\alpha$ and interleukin- $1 \beta$ at the site of injury result in the expression of adhesion molecules on the surface of leukocytes and endothelial cells that guide the process of rolling, leukocyte capture, attachment, and transmigration $(20,21)$. This results in the passage of the leukocyte from the vascular bed into the surrounding tissues. Platelets, one of the first cellular elements at the site of injury, also contribute to this process. Degranulating platelets release contents of their $\alpha$ granules that include P-selectin, which is important in leukocyte rolling $(17,19)$. The relative differences in function and cytokine content of fetal and adult platelets have been previously described (22-25). However, the ability of fetal endothelial cells to enable leukocyte trafficking has not been carefully elucidated. Leukocyte counts differ at various stages of gestation, and there is a relative leukopenia compared with adult values. In addition, leukocytes from immature hosts are generally thought to be less adept than adult leukocytes (26). To eliminate this variable in our experimental system, only adult neutrophils were used for the study. In this study, we have shown that fetal endothelial cells are capable of recruiting neutrophils to the site of inflammation and that the response could be dependent on the amount of proinflammatory cytokines in the microenvironment. However, at the same concentration of TNF- $\alpha$, the fetal endothelial cell inflammatory response in this in vitro model is

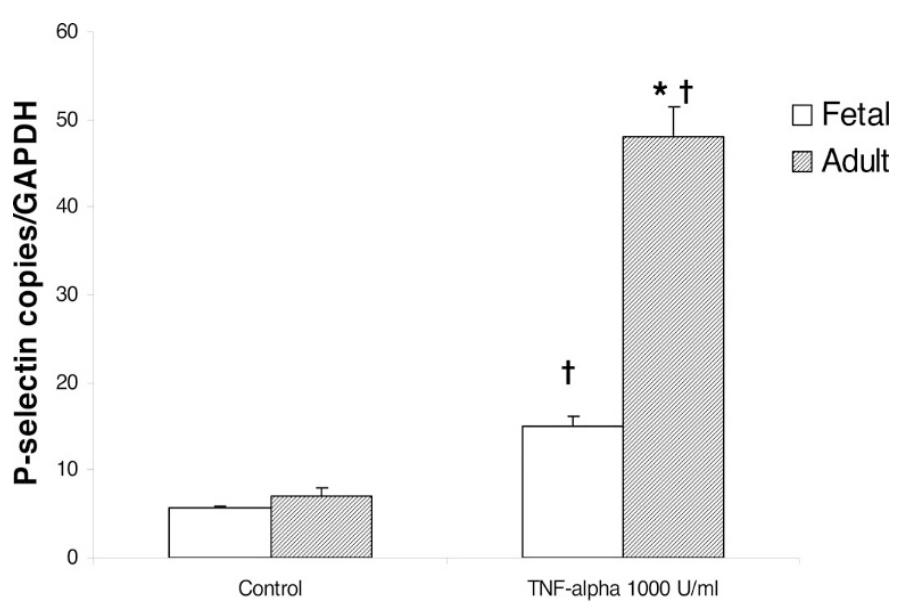

Figure 6. Expression of P-selectin mRNA in fetal and adult endothelial cells. Without stimulation, the P-selectin/GAPDH mRNA expression ratio was similar in fetal and adult endothelial cells $(5.71 \pm 0.17$ and $7.07 \pm 0.96$, respectively) Following stimulation with TNF- $\alpha 1000 \mathrm{U} / \mathrm{mL}$, the fetal expression was $15.07 \pm 1.05$ and the adult $48.05 \pm 3.37$. Values are mean \pm SEM of the ratio of $10^{4}$ P-selectin copies per $10^{6}$ GAPDH copies. $\dagger p<0.05$ compared with control. * $p<0.05$ compared with fetus. 
significantly less than that of adult endothelial cells. While the proportion of adherent neutrophils that ultimately transmigrate was similar in both adult and fetal monolayers, the absolute number of transmigrated cells was much lower in the fetal group since fewer cells were adherent. In vivo, these transmigrated cells will then release cytokines, chemokines, and growth factors to the extravascular compartment and contribute to the response to injury. P-selectin is an important molecule in the initial phase of leukocyte trafficking. It binds to P-selectin glycoprotein ligand on the neutrophil, thus slowing the transit of the neutrophil in the bloodstream and subsequently permitting firm adhesion by other adhesion molecules. In this study, we have been able to show a significant reduction in P-selectin mRNA expression in keeping with the faster rolling velocity along the fetal endothelial cells. Although we have thus far been unsuccessful in generating a reliable antibody to porcine P-selectin, the rolling velocity observations suggest a decreased expression of this protein on the membrane on fetal endothelial cells.

Several authors have shown that provoking an inflammatory response in fetal wounds results in increased fibroplasias $(8,9)$. Other authors have suggested a relative lack of cytokines in the fetus $(27,28)$. Thus, it appears that the fetus has an inherent system that limits the inflammatory response compared with adult. We had previously shown that fetal platelets release fewer cytokines following degranulation and were less likely to aggregate in response to collagen exposed at the site of injury (23-25). These factors, coupled with the decreased ability of fetal endothelial cells to recruit neutrophils, may explain in part the minimal inflammatory response seen at the site of fetal dermal wounds. These findings provide further insight into the unique fetal response to healing and may offer alternative avenues to modulate the postnatal wound-healing response. In addition, a better understanding of the fetal inflammatory response may provide insight into the predisposition of these immature hosts to infectious complications.

\section{REFERENCES}

1. Carrico TJ, Mehrhof AI Jr, Cohen IK 1984 Biology of wound healing. Surg Clin North Am 64:721-733

2. Hackam DJ, Ford HR 2002 Cellular, biochemical, and clinical aspects of wound healing. Surg Infect (Larchmt) 1(3 suppl):S23-35

3. Rowlatt U 1979 Intrauterine healing in a 20-week human fetus. Virchows Arch 381:353-361

4. Adzick NS, Longaker Michael T 1992 Characteristics of fetal tissue repair. In: Adzick NS, Longaker MT (eds) Fetal Wound Healing, Elsevier, New York, pp 53-70
5. Longaker MT, Peled ZM, Chang J, Krummel TM 2001 Fetal wound healing: progress report and future directions. Surgery 130:785-787

6. Bullard KM, Longaker MT, Lorenz HP 2003 Fetal wound healing: current biology. World J Surg 27:54-61

7. Colwell AS, Longaker MT, Lorenz HP 2003 Fetal wound healing. Front Biosci 8:s1240-s1248

8. Frantz FW, Bettinger DA, Haynes JH, Johnson DE, Harvey KM, Dalton HP, Yager DR, Diegelmann RF, Cohen IK 1993 Biology of fetal repair: the presence of bacteria in fetal wounds induces an adult-like healing response. J Pediatr Surg 28:428-434

9. Haynes JH, Johnson DE, Mast BA, Diegelmann RF, Salzberg DA, Cohen IK, Krummel TM 1994 Platelet-derived growth factor induces fetal wound fibrosis. J Pediatr Surg 29:1405-1408

10. Krummel TM, Michna BA, Thomas BL, Sporn MB, Nelson JM, Salzberg AM, Cohen IK, Diegelmann RF 1988 Transforming growth factor beta (TGF-beta) induces fibrosis in a fetal wound model. J Pediatr Surg 23:647-52

11. Smith CW, Marlin SD, Rothlein R, Toman C, Anderson DC 1989 Cooperative interactions of LFA-1 and Mac-1 with intercellular adhesion molecule-1 in facilitating adherence and transendothelial migration of human neutrophils in vitro. J Clin Invest 83:2008-2017

12. Jaffe EA, Nachman RL, Becker CG, Minick CR 1973 Culture of human endothelial cells derived from umbilical veins. Identification by morphologic and immunologic criteria. J Clin Invest 52:2745-2756

13. Ford JW, Burkel WE, Kahn RH 1981 Isolation of adult canine venous endothelium for tissue culture. In Vitro 17:44-50

14. Entman ML, Youker K, Shappell SB, Siegel C, Rothlein R, Dreyer WJ, Schmalstieg FC, Smith CW 1990 Neutrophil adherence to isolated adult canine myocytes. Evidence for a CD18-dependent mechanism. J Clin Invest 85:1497-1506.

15. Boyum A 1968 Isolation of leucocytes from human blood. A two-phase system for removal of red cells with methylcellulose as erythrocyte-aggregating agent. Scand J Clin Lab Invest Suppl 97:9-29

16. Boyum A 1968 Isolation of mononuclear cells and granulocytes from human blood. Isolation of mononuclear cells by one centrifugation, and of granulocytes by combining centrifugation and sedimentation at $1 \mathrm{~g}$. Scand J Clin Lab Invest Suppl 97:77-89

17. Jones DA, Abbassi O, McIntire LV, McEver RP, Smith CW 1993 P-selectin mediates neutrophil rolling on histamine-stimulated endothelial cells. Biophys J 65:1560-1569

18. Abbassi O, Kishimoto TK, McIntire LV, Anderson DC, Smith CW 1993 E-selectin supports neutrophil rolling in vitro under conditions of flow. J Clin Invest 92:2719 2730

19. Mariscalco MM, Tcharmtchi MH, Smith CW 1998 P-Selectin support of neonatal neutrophil adherence under flow: contribution of L-selectin, LFA-1, and ligand(s) for P-selectin. Blood 91:4776-4785

20. Springer TA 1995 Traffic signals on endothelium for lymphocyte recirculation and leukocyte emigration. Annu Rev Physiol 57:827-872

21. Granger DN, Kubes P 1994 The microcirculation and inflammation: modulation of leukocyte-endothelial cell adhesion. J Leukoc Biol 55:662-675

22. Olutoye OO, Barone EJ, Yager DR, Uchida T, Cohen IK, Diegelmann RF 1997 Hyaluronic acid inhibits fetal platelet function: implications in scarless healing. J Pediatr Surg 32:1037-1040

23. Olutoye OO, Barone EJ, Yager DR, Cohen IK, Diegelmann RF 1997 Collagen induces cytokine release by fetal platelets: implications in scarless healing. J Pediatr Surg 32:827-830

24. Olutoye OO, Yager DR, Cohen IK, Diegelmann RF 1996 Lower cytokine release by fetal porcine platelets: a possible explanation for reduced inflammation after fetal wounding. J Pediatr Surg 31:91-95

25. Olutoye OO, Alaish SM, Carr ME Jr., Paik, M, Yager DR, Cohen IK, Diegelmann RF 1995 Aggregatory characteristics and expression of the collagen adhesion receptor in fetal porcine platelets. J Pediatr Surg 30:1649-1653

26. Anderson DC, Hughes BJ, Smith CW 1981 Abnormal mobility of neonatal polymorphonuclear leukocytes. Relationship to impaired redistribution of surface adhesion sites by chemotactic factor or colchicine. J Clin Invest 68:863-874

27. Liechty KW, Adzick NS, Crombleholme TM 2000 Diminished interleukin 6 (IL-6) production during scarless human fetal wound repair. Cytokine 12:671-676

28. Sullivan KM, Lorenz HP, Meuli M, Lin RY, Adzick NS 1995 A model of scarless human fetal wound repair is deficient in transforming growth factor beta. J Pediatr Surg 30:198-203 